University of Texas Rio Grande Valley

ScholarWorks @ UTRGV

$5-19-2020$

\title{
Understanding Crowdsourcing Contest Fitness Strategic Decision Factors and Performance: An Expectation-Confirmation Theory Perspective
}

Emmanuel Wusuhon Yanibo Ayaburi

The University of Texas Rio Grande Valley

Jaeung Lee

Michele Maasberg

Follow this and additional works at: https://scholarworks.utrgv.edu/is_fac

Part of the Business Commons

\section{Recommended Citation}

Ayaburi, E.W., Lee, J. \& Maasberg, M. Understanding Crowdsourcing Contest Fitness Strategic Decision Factors and Performance: An Expectation-Confirmation Theory Perspective. Inf Syst Front 22, 1227-1240 (2020). https://doi.org/10.1007/s10796-019-09926-w

This Article is brought to you for free and open access by the Robert C. Vackar College of Business \& Entrepreneurship at ScholarWorks @ UTRGV. It has been accepted for inclusion in Information Systems Faculty Publications and Presentations by an authorized administrator of ScholarWorks @ UTRGV. For more information, please contact justin.white@utrgv.edu,william.flores01@utrgv.edu. 


\title{
Understanding Crowdsourcing Contest Fitness Strategic Decision Factors and Performance: An Expectation-Confirmation Theory Perspective
}

\author{
Emmanuel Ayaburi ${ }^{1, *}{ }^{*}$ aeung Lee $^{2}$ Michele Maasberg ${ }^{2}$ \\ ${ }^{1}$ Department of Information Systems, The University of Texas Rio Grande Valley, Edinburg, TX, US \\ ${ }^{2}$ Department of Computer Information Systems, Louisiana Tech University, Ruston, LA, USA \\ *Corresponding author. \\ Emmanuel Ayaburi, Ph.D., \\ The University of Texas Rio Grande Valley, \\ 1201 W. University Dr. Edinburg, Texas 78539, USA; \\ Tel: + 19566652822; \\ Email address: emmanuel.ayaburi@utrgv.edu
}

\begin{abstract}
Contest-based intermediary crowdsourcing represents a powerful new business model for generating ideas or solutions by engaging the crowd through an online competition. Prior research has examined motivating factors such as increased monetary reward or demotivating factors such as project requirement ambiguity. However, problematic issues related to crowd contest fitness have received little attention, particularly with regard to crowd strategic decision-making and contest outcomes that are critical for success of crowdsourcing platforms as well as implementation of crowdsourcing models in organizations. Using Expectation-Confirmation Theory (ECT), we take a different approach that focuses on contest level outcomes by developing a model to explain contest duration and performance. We postulate these contest outcomes are a function of managing crowdsourcing participant contestfitness expectations and disconfirmation, particularly during the bidding process. Our empirical results show that contest fitness expectations and disconfirmation have an overall positive effect on contest performance. This study contributes to theory by demonstrating the adaptability of ECT literature to the online crowdsourcing domain at the level of the project contest. For practice, important insights regarding strategic decision making and understanding how crowd contest-fitness are observed for enhancing outcomes related to platform viability and successful organizational implementation.
\end{abstract}

Keywords: Crowdsourcing, Contest-fitness, Expectation, Confirmation, Duration, Performance 


\section{Understanding Crowdsourcing Contest Fitness Strategic Decision Factors and Performance: An Expectation-Confirmation Theory Perspective}

\section{Introduction}

Crowdsourcing refers to the process of a crowd-seeker tapping the intellect of a large pool of independent individuals (usually referred to as "crowd") to either collaboratively or competitively fulfil the requirements of a project normally delegated to employees in an organization (Geiger \& Schader, 2014) or a task that requires human judgement (Xiao, 2014). Advances in technology and electronic commerce have led to the establishment of thirdparty platforms known as intermediary crowdsourcing platforms to match business needs of institutions to the skills of the crowd who are usually outside the institution. In a typical intermediary crowdsourcing context, three entities are involved: 1) crowd-seekers; 2) platform operators; and 3) crowd. The crowd-seeker posts a project on the intermediary crowdsourcing platform with project requirements along with a fixed reward amount for the crowd member and the best solution selected. The crowd competes against each other and submits the best solution in the form of a bid. The term bid is used because crowdsourcing competitions can be modeled as an auction (Chawla, Hartline, \& Sivan, 2015) (see section 2.2 for additional discussion).

Contest-based crowdsourcing platforms promote competition among the crowd in order to find the best solution for the seeker. Examples of contest-based intermediary crowdsourcing platforms include InnoCentive and crowdSPRING. These and other intermediary crowdsourcing platforms have experienced tremendous growth since their emergence in early 2000s (Taylor, 2017). For instance, intermediary crowdsourcing platform HackerOne that connects a crowd interested in searching for flaws in software with crowd seeking organizations has over 200,000 registered users where the top $3 \%$ of the crowd make over $\$ 100,000$ annually (Giles, 2018). Despite the successful use of the crowdsourcing business model to find solutions for businesses, only a few companies, such as ColgatePalmolive and Tongal, have advantageously harnessed the crowd in a contest (Boudreau \& Lakhani, 2013). On the other hand, numerous cases of failed crowdsourcing platforms also exist, such as CrowdSpirit and Cambrian House (Schonfeld, 2008). The success of a crowdsourcing business model for an organization depends on overcoming management challenges such as decreased crowd participation, crowd-seeker retention, and performance of projects. Additionally, the success of the intermediary platforms depends on the motivation of the crowd, transparency of the 
market, participation by both the crowd and seekers, and performance of the projects in the contests. A common outcome for success noted for successful use of crowdsourcing as a business model and success of crowdsourcing platforms is performance of the projects. Another key outcome to consider is duration of the contest, since crowdsourcing contests are organized like auctions, and impatient participants may exit the market (Haruvy \& Leszczyc, 2010). Addressing these outcomes requires investigating contest characteristics, particularly assuring that a match is coordinated between crowd-seeker and crowd to improve contest fitness. Ensuring crowd contest-fitness requires understanding strategic decision making on the part of the crowd, and it requires proactive information and feedback provisioning by crowd seekers so that the crowd member can make an accurate bid.

Figure 1 shows a schematic illustration of the strategic decision-making process in a contest-based intermediary crowdsourcing platform.

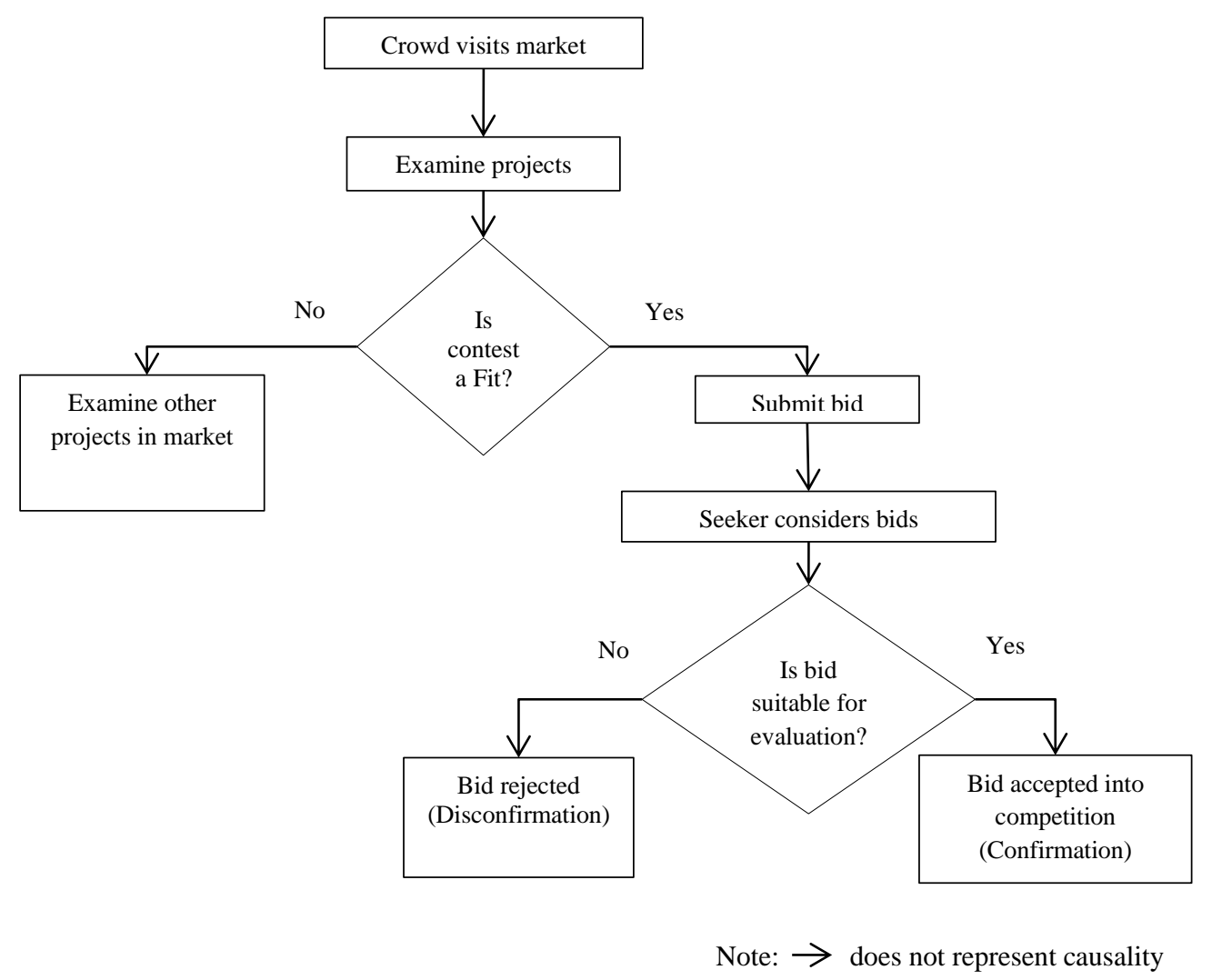

Fig 1. Typical crowd/seeker decision-making process in contest-based crowdsourcing

A crowd member visits a platform (see illustration in Figure 1) expecting to find a suitable contest in which to participate. The crowd members usually examine listed projects to identify whether their skills match a project requirements. Once the crowd member finds a matching project, the individual decides whether to engage in that 
project contest based on assessment of the contest characteristics. If individuals from the crowd perceive a fit with a particular project contest, they will submit a bid. Following the submission of bids, the seeker confirms the acceptability of the bid for evaluation. The bid confirmation/disconfirmation process results in the final set of bids evaluated by the seeker and the selection of one winner from the crowd. The level of disconfirmation of bids greatly affects members of the crowd regarding their decision to participate. In marketing literature, the confirmation or disconfirmation of the expectations of individuals in the service industry has been posited to affect intensity and level of engagement in the service. Therefore, the bid disconfirmation phenomenon on an intermediary crowdsourcing platform presents an interesting area of study with respect to a crowd's contest fitness expectation and strategic decision making (Oliver, 1980).

Hence, the purpose of this research is to examine strategic decision making about contest-fitness and how expectations of the crowd and the rejection of bids (disconfirmation) by crowd seekers affect outcomes in intermediary crowdsourcing markets. Specifically, we seek to answer the following research questions:

1. How does crowd expectation in the form of contest-fitness influence online contest-based intermediary crowdsourcing markets?

2. How does bid disconfirmation affect contest outcomes in online contest-based intermediary crowdsourcing markets?

We postulate that participants in intermediary crowdsourcing markets are rational agents who want to enhance their reputation in crowdsourced contests as well as maximize their economic benefit based on the confirmation or disconfirmation of their expectations on the online platform through the acceptance or rejection of their bids for consideration by the seeker. Understanding the dynamics of participants during the bidding process is vital to quickly, accurately, and efficiently match crowd and crowd seeker for a shorter contest period and completing projects on schedule. Therefore, managing expectations of the crowd for a project match, specifically during the bidding process, is an important area to study as it can removing barriers to the conduct and completion of business. Crowd expectations management requires examining strategic decision making and understanding the contest fitness issues with all participants and the effect on contest outcomes. Therefore, to answer the research questions, we use Expectation-Confirmation Theory (ECT) (Oliver, 1977) as the basis to investigate performance of intermediary crowdsourcing at the contest level. ECT has been used to explain sustainability in online communities (Cheung \& Lee, 2009; Gräuler, Freundlieb, Ortwerth, \& Teuteberg, 2013); we adapt it to understand crowd and crowd-seeker 
contest fitness expectations and disconfirmation including how these variables impact outcomes in a crowdsourcing contest. Using objective data from a crowdsourcing platform, we complement prior research on ECT by examining the factors related to strategic decision making by participants that influence the duration and performance of a contest. This study extends the ECT sustainability literature to the crowdsourcing context. By examining outcome variables noted to be important to the sustainability and success of crowdsourcing contests, we provide insights for developing intermediary crowdsourcing platforms and for implementing the crowdsourcing business model.

The remainder of the paper is structured as follows. In the next section, a review of related literature on crowdsourcing contests and online auctions is presented. Subsequently, the theoretical background and hypotheses are presented followed by the methodology used to gather data and test the hypotheses advanced in the study. In the analysis and discussion section, the theoretical and practical implications of the findings are discussed. The study concludes with limitations and avenues for future research.

\section{Related literature}

Recent research level in the contest-based crowdsourcing domain has increased with the significant use of crowdsourcing to supplement the internal workforce in fulfilment of business needs,. This study draws primarily from competitive intermediary crowdsourcing and online auction streams of research. We build on these related studies to highlight the need to address intermediary crowdsourcing sustainability challenges by examining what influences contest outcomes through a new lens related to strategic decision making and crowd contest fitness.

\subsection{Competitive intermediary crowdsourcing}

Prior research on intermediary crowdsourcing has focused particularly on identification of challenges facing the platforms such as, 1) motivation of both seeker and the crowd to participate, 2) accurately assessing the quality of submitted bids, 3) facilitating a smooth transaction/bidding process, 4) efficient matching of demand with supply, and 5) ensuring credible reputation systems as key drivers affecting the sustainability of the crowdsourcing business model (Kajino, Arai, \& Kashima, 2014). Other prior research has addressed the challenges regarding motivation and efficient matching, and has concluded that ensuring anonymity for the crowd and implementing of personalized project recommendation mechanisms are critical for platforms success (Geiger \& Schader, 2014). Although findings from this research demonstrated that imposing anonymity among the crowd reduced bias in a crowd-seeker's evaluation of the crowd's work and can serve as a quality control method (Kajino et al., 2014), we argue that such a mechanism 
heightens uncertainty for a crowd-seeker who desires to incorporate the crowds' prior record of accomplishment in accepting bids from qualified and reputable crowd members for evaluation. Although the personalized project recommendation mechanism might address issues in an anonymous environment and provide a more efficient matching between projects and professionals, only targeted skilled crowd members with an established reputation will be recommended to participate in a project contest (Geiger \& Schader, 2014)). This combination deviates from the idea of diverse advertising to a vast crowd and hampers the ability to harness new talent. Therefore, there is room to extend current research to address the challenges related to crowd sourcing sustainability, particularly with regard to assisting all participants with understanding the competitive environment so that the bidding process is smooth and quality bids are submitted, enhancing performance in a broad and diverse environment.

Competitive intermediary crowdsourcing such as the one considered in this study favors an open and transparent competition through broad participation by all agents. The more information that is available to an active crowd (i.e., including crowd members who participate in several project contests within a given period of time), the more informed decisions the seekers can make regarding acceptance of bids. On the other hand, when more crowd seeker actions are available to all participants, it impacts the level of enthusiasm of the other onlooking crowd (Bayus, 2013). Therefore, the nature of the competitive crowdsourcing business model calls for more innovative approaches to promote information transparency, proactive and accurate information, and timely feedback. This will assist participants in making more strategic decisions as they can manage expectations make an informed decision about either their fitness for a contest.

Promotion of intense open competition for engagement opportunities for the crowd enables a chance to win and increases the diversity of solutions for the crowd seeker (Djelassi \& Decoopman, 2013). The nature of the competition in intermediary crowdsourcing has not been well studied. This is particularly important as crowd incurs a sunk cost after having invested significant resources in a project contest, and their bid is not accepted for evaluation, or the contest turns out unsuccessful. Increased competition, along with effective feedback for participants is important to the crowd working earnestly to submit competitive bids (Bolton, Loebbecke, \& Ockenfels, 2008). Prior research (see Table 1) has not objectively evaluated outcomes including duration of a contest nor its performance consequence. These are important outcomes because they affect the selection process of a winning bid, management of crowd expectations, and the decision of a crow seeker to not accept some bids for consideration. Contest duration affects the intensity of the bidding process and eventually the performance of the contest. To further examine crowdsourcing 
contest outcomes and antecedents and strategic decision-making antecedents, we critically analyze online auction competition literature for further insights.

\subsection{Online auction competition}

Contest-based intermediary crowdsourcing adopts the outsourcing business model yet employs the concept of auction competition to assess the intelligence of a distributed crowd (Chanal \& Caron-Fasan, 2010; Schenk \& Claude, 2011). By incorporating features of online auctions and outsourcing, intermediary crowdsourcing has expanded to include the concept of bidding due to the ease of access and lower cost of participation by both crowd and crowdseeker.

However, the nature and process of bidding in intermediary crowdsourcing is more complicated than in the regular online auction setting. There are non-trivial costs of participating in intermediary crowdsourcing by members of the crowd, as they are required to submit prototypes or fully-fledged products. Therefore, bidders (the crowd) are less likely to be risk-neutral than they would be in the absence of these costs. In addition, unlike a traditional auction competition where bidders can observe competing prices and re-adjusts their bids, crowd members in intermediary crowdsourcing contests need to have their bids accepted by the seeker to be considered for evaluations. This could lead to undesirable outcomes where crowd's bids could be rejected or disconfirmed prior to the closure of the competition or before a winner is selected from the pool of submitted bids. This affects the participation dynamics of crowd members in crowdsourcing competitions and results in each member of the crowd developing unique bidding strategies.

The success of a crowdsourcing competition relies on carefully balancing the relation between demand and supply. Therefore, in addition to crowdsourcing success factors such as an efficient Information Technology (IT) infrastructure and good reputation mechanisms, contest-base intermediary crowdsourcing platforms need to control the volatile participation level of the crowd resulting from the uncertainties/expectation they have on the platform (Klein \& Teubner, 2000). This requires taking a closer look at crowd expectations, how they interface with crowd seeker confirmation/disconfirmation process through disposition of the bid, and how these dynamics affect contest outcomes. Table 1 shows prior research in competitive intermediary crowdsourcing and auction competition literature that have examined contest outcomes related to platform challenges in the areas of quality, bidding, and supply and demand related to platform sustainability. 
Table 1 Key competitive intermediary crowdsourcing and auction competition research

\begin{tabular}{|l|l|l|l|}
\hline Reference & Outcome & Theory & Findings \\
\hline (Zheng, 2014) & Quality and diversity & Extrinsic Motivation & $\begin{array}{l}\text { Quantity and diversity of } \\
\text { solutions affect quality outcome } \\
\text { of crowdsourcing contest. }\end{array}$ \\
\hline $\begin{array}{l}\text { (Leimeister, Huber, } \\
\text { Bretschneider, \& }\end{array}$ & Increased competition & $\begin{array}{l}\text { Motive-Incentive- } \\
\text { Activation-Behavior } \\
\text { Model }\end{array}$ & $\begin{array}{l}\text { Increased competition depends } \\
\text { on incentives and motives such } \\
\text { as psychological fulfilment of } \\
\text { submitting a good bid }\end{array}$ \\
\hline $\begin{array}{l}\text { (Bullinger, Neyer, Rass, } \\
\text { \& Moeslein, 2010) }\end{array}$ & Innovativeness & $\begin{array}{l}\text { Boundary spanning } \\
\text { perspective }\end{array}$ & $\begin{array}{l}\text { Degree of cooperative } \\
\text { orientation among crowd results } \\
\text { in a high degree of } \\
\text { innovativeness }\end{array}$ \\
\hline $\begin{array}{l}\text { (Satzger, Psaier, Schall, } \\
\text { \& Dustdar, 2013) }\end{array}$ & Quality & $\begin{array}{l}\text { Ensuring high quality solution } \\
\text { lies in skilled members whose } \\
\text { capabilities can be estimated } \\
\text { correctly }\end{array}$ \\
\hline $\begin{array}{l}\text { (Liu, Yang, Adamic, \& } \\
\text { Chen, 2014) }\end{array}$ & Contest outcome & Auction Framework & $\begin{array}{l}\text { In addition to the positive effect } \\
\text { of reward on contest outcome, } \\
\text { quality individuals in the crowd } \\
\text { are likely to not to participate if } \\
\text { they perceive already submitted } \\
\text { bids to be of higher quality }\end{array}$ \\
\hline
\end{tabular}

Table 1 shows that outcomes related to quality, increased competition, and innovation have been examined with findings that psychological and motivational (particularly extrinsic) antecedents affect the contest outcomes. These incentives and motives involved with bidding affect competition and quality of solutions. However, research opportunities exist surrounding the dynamics involved with strategic decision making by participants as it relates to crowd contest-fitness, particularly managing expectations of the crowd and the bid confirmation/disconfirmation process as antecedents of contest outcomes. Contest duration as an important metric of crowdsourcing platforms as well as performance as a metric of past platform failures are examined as contest outcomes. While previous research relied on motivational and auction frameworks, we look to ECT as an alternate theoretical lens to incorporate the examination of contest fitness expectation and disconfirmation as antecedents to contest outcomes. 


\section{Theoretical background and model development}

\subsection{Expectation-Confirmation Theory}

Expectation-confirmation theory (ECT), also referred to as a model of expectation-confirmation (Brown, Venkatesh, \& Goyal, 2012), expectation-disconfirmation effects (McKinney, Yoon, \& Zahedi, 2002), and expectation-disconfirmation theory (Bhattacherjee \& Premkumar, 2004; Lankton, McKnight, Wright, \& Thatcher, 2016), was initiated as a framework in marketing studies in the context of products to examine the effects on perceived performance of a perceived disconfirmation experience related to whether expectations were met after individuals form an initial expectation about the product (Oliver, 1977). Follow on studies introduced the theoretical framework in the context of consumer satisfaction to understand intentions to repurchase a product where disconfirmation and satisfaction were found to be highly correlated using a student sample (Oliver, 1980). ECT has been extended to the IS domain to include intention to continue using IS (IS continuance) (Bhattacherjee, 2001; Venkatesh, Thong, Chan, Hu, \& Brown, 2011), IT usage in the context of end user training with computer based training (Bhattacherjee \& Premkumar, 2004), technology use (Brown et al., 2012), trust in technology (Lankton et al., 2016), web customer satisfaction (McKinney et al., 2002), and online sustainability (Gräuler et al., 2013).

We extend ECT to an online crowdsourcing contest environment, where dynamics involving expectations of the crowd coupled with the complexity of confirmation/disconfirmation during the bidding process are examined with regard to contest outcomes. Crowd members form an expectation about their fitness for the contest when they visit a platform (see Fig. 1), and that expectation is confirmed (or disconfirmed) when their bids are accepted (or not) by the crowd-seeker for evaluation. Disconfirmation of their bids may lead to dissatisfied crowd members. Although crowd members might be dissatisfied by the disconfirmation of their bids, the disconfirmation process impacts their enthusiasm towards the contest as they better understand the expectations of the crowd-seekers and re-evaluate their contest fitness, and become more strategic in their bid submissions. When the crowd members submit suitable bids, the crowd seeker's initial goal is accomplished and they will experience satisfaction with the crowd and the platform. We aim to complement prior literature by extending ECT to online labor markets at the contest level and include outcomes that rely on strategic decision making of all agents to remain a viable business model including understanding the importance of managing crowd expectations to facilitate precise bidding as they assess their contest fit as a strategic decision. 
Expectations are formed by the crowd about a project prior to submission of a bid. These expectations and the subsequent confirmation or disconfirmation of the bid are argued to have a significant impact on contest outcomes duration and performance. The crowd in intermediary crowdsourcing are assumed to be rational agents making reasoned judgments based on a cost-benefit analysis of the intended acts, as demonstrated in Figure 1. Although rationality is primarily motivated by uncertainty and expectations (Hastie \& Dawes, 2010), when the optimal individual outcome depends on uncertain environmental events or the actions of other rational agent in the transaction, there is the need to employ substantive criteria broad enough to extend the concept of rationality beyond purely costbenefit analysis (Simon, 1978). For instance, the decision of a member of the crowd to engage in a project contest is influenced by their contest fitness assessment to start the process. We therefore use ECT to set the stage for understanding how expectations of the crowd and disconfirmation by the crowd-seeker of bids affect contest outcome. When the crowd foresee high unfitness in a contest, their expectations are affected. Similarly, a crowd-seeker with information about crowd member pattern is able to make better informed decisions regarding quality bids. This leads us to examination of a model for understanding how these dynamics affect contest outcomes. Next, we develop a research model extending key components of ECT.

\subsection{Expectation-Confirmation Model of a Crowdsourcing Contest}

\subsubsection{Crowd expectation and crowd seekers disconfirmation}

The crowd receives psychological benefits such as status or acclaim when they are successful in a project contest. Therefore, when crowd members engage in online competitions or auctions such as an intermediary crowdsourcing project contest, the may not be doing so from a purely economic perspective (Zheng, Li, \& Hou, 2011). The psychological benefits gained from a project contest are diminished when members of the crowd observe that submitted bid are being rejected (disconfirmed) for evaluation by the crowd-seeker. The crowd will evaluate the efficacy of their skills to identify their fit with a contest. Uncertainty among the crowd will affect the crafting of suitable bids. This is because the crowd is unable to anticipate the subjective judgement of the crowd-seeker. Increased bid disconfirmation creates a new risk (Kim, Ferrin, \& Rao, 2008) for the crowd members as they now have 1) uncertainty about the needs of the seeker and 2) uncertainty about the interest of the seeker in realizing a successful project. The crowd-seeker decision regarding metrics for suitable bids depends on subjective bid quality, which is often not explicitly descriptive in their project requirements. Therefore, any uncertainty in the expectations of the 
crowd about their fitness for a contest would affect the ability to create a winnable bid, and more unsuitable bids might be placed due to the high uncertainty about contest fitness. Therefore, we hypothesize:

H1: The level of contest fitness expectation among the crowd in a crowdsourced project contest is positively associated with the contest fitness disconfirmation by the crowd seeker in an intermediary contest-based crowdsourcing market.

\subsubsection{Contest fitness disconfirmation and contest outcomes}

Disconfirmation of bids reduces the number of bids available for crowd-seeker evaluation and decreasing the chance of finding a suitable bid. A crowd-seeker interested in successfully closing the contest with a suitable bid may extend the duration of the contest to allow for more submission of bids. In traditional auction settings, auctions duration has been shown to be negatively correlated with increasing bid submission (Haruvy \& Leszczyc, 2010). Therefore, a crowd member who plans to join a contest may become hesitant to construct and place a bid if most bids submitted are already disconfirmed (regarded as unsuitable) by the seeker and their expectation about their fitness for the contest are not met. Increased bid disconfirmation could mean that the crowd will observe the seeker behavior a little longer to understand their project needs. Therefore, it will take extra time to design suitable bids for the seeker. The crowdseeker would therefore have to extend the duration of the contest to receive a higher number of bids. Crowd members engaging in any contest will attempt to maximize their utility by making strategic choices that have the potential to heighten their success. Therefore, we postulate that a project contest's duration will be affected by the level of perceived unsuitable bids submitted such that:

H2: The level of contest fitness disconfirmation in a crowdsourced project contest is positively associated with contest duration in an intermediary contest-based crowdsourcing market.

At the end of every contest in intermediary market, the contest is scored by the operator relative to other projects on its attractiveness to the crowd and the quality of bids submitted. Contest performance is the direct result of metrics from all participating crowd members (Javadi Khasraghi \& Aghaie, 2014). We argue that disconfirmation of bids would influence project contest score. A crowd member who plans to join a contest may pay attention to a high bid disconfirmation rate by a crowd-seeker if the information is available. Crowd members might interpret the high bid disconfirmation rate by seeker to mean that the seeker is selective. Crowd members will try to make strategic choices that have the potential to their success. Overall, we expect that disconfirmation of bids will lead to crowd-seeker receiving only bids that meet their subject quality threshold. Thus, the final bids to be considered by the seeker would be of greater quality for a higher performing contest due to the filtering process. Therefore, we postulate that a project contest's performance would be affected such that: 
H3: The level of contest fitness disconfirmation in a crowdsourced project contest is positively associated with contest performance in an intermediary contest-based crowdsourcing market.

\subsubsection{Contest fitness expectation and contest outcomes}

Duration is an important measure of outcomes in auction literature, and it is considered due to intermediary crowdsourcing sharing common characteristics to online auctions as discussed in section 2.2. When an auction takes too long, good but impatient bidders may opt out of the contest or revise their submission decision (bid) (Haruvy \& Leszczyc, 2010). Because of the non-trivial cost of bid preparation, crowd members will pay attention to the requirements of a project, evaluate the expectations of their fit for the contest (capability of producing a suitable bid) before making an efforts to submit a bid. Past research has shown that an individual's level of uncertainty about their competence affect their decision to engage in activity or perform a task (Pe-Than, Goh, \& Lee, 2017). This could affect crowd members as their contest fitness expectations could cause them to doubt their competency for projects, particularly without information transparency. It would then take crowd member more effort, time, and resources to submit quality of bids if their expectations in the presence of uncertainty. Members of the crowd would also take more time to try to be selective in their choice of projects to increase their chances of success, also prolonging contest duration. Members of the crowd may contemplate not joining a contest because they consider their interests are not being maximized based on the nature of competition (Lin \& Huang, 2010), which would also prolong contests. Finally, a crowd-seeker may have to provide additional feedback to crowd members causing a longer contest duration if expectations are not properly managed in order to facilitate a reasonable of submission before deciding to evaluate the bids. Hence, we hypothesize:

H4: The level of contest fitness expectation by the crowd in a crowdsourced project contest is positively associated with the contest duration in an intermediary contest-based crowdsourcing market.

The nature of the competition in intermediary crowdsourcing can elicit crowd feelings of exploitation and being cheated after investing significant resources in a project contest that turns out unsuccessful, particularly when their bids have been disconfirmed. Based on ECT, when expectations are not met, actors could be demotivated, and they could either leave the platform or become disengaged as they anticipate lower social value (Yu, Zo, Kee Choi, \& P. Ciganek, 2013). Demotivation from the unmet expectations is expected to impact project performance in the form poor quality of submitted bids (Schonfeld, 2008). Thus, over the long run due to the nontrivial cost of contest participation, unmet expectations in the form of contest-fitness would negatively affect motivation for engagement by 
the crowd. Lower levels of motivation lead to the crafting of bids of lower quality or exit from the contest because crowd expectations were too high from misunderstanding the contest fit. Therefore, we argue that:

H5: The level of contest fitness expectation by the crowd in a crowdsourced project contest is negatively associated with the contest performance in an intermediary contest-based crowdsourcing market.

\subsubsection{Contest duration and performance}

At the end of every contest on the platform, the contest performance is scored relative to other projects on its attractiveness to the professionals, the quality of bids submitted and participants' satisfaction. Project score is the direct result of the crowd performance (Javadi Khasraghi \& Aghaie, 2014). When a project is listed in the crowdsourcing market for a long time causing a long contest duration, it might be the result of lack of interest from the crowd (if not from the aforementioned issues) and could possibly lead to transaction failure. The potential lack of interest in the contest or issues from participant contest fitness causing long duration in contest may results in a low project contest performance (Boudreau, Lacetera, \& Lakhani, 2011). Therefore, we hypothesize:

H6: The contest duration of a crowdsourced project is negatively associated with the contest performance in an intermediary contest-based crowdsourcing market.

Figure 2 summarizes our research model.

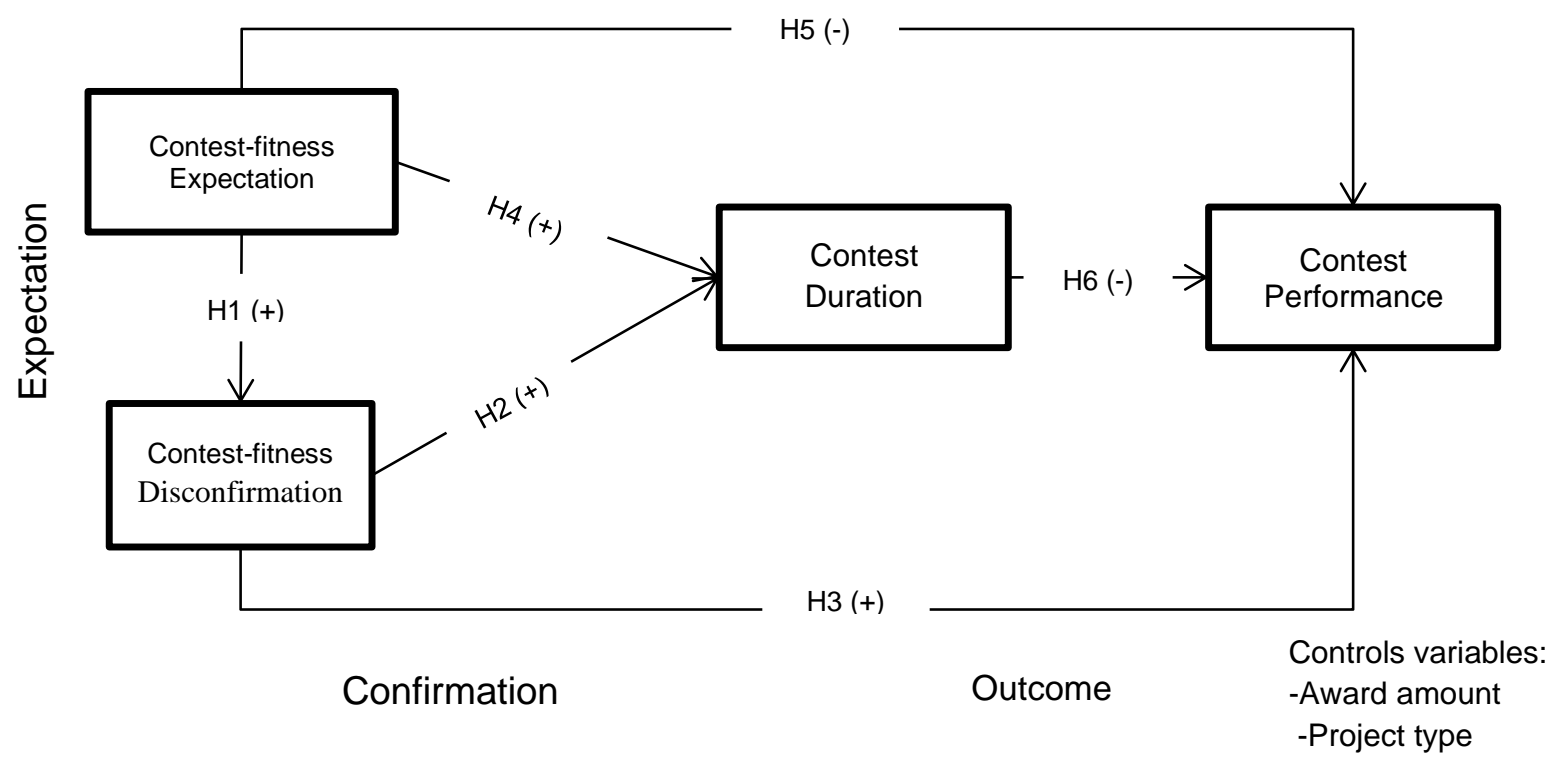

Fig. 2: Research model

\section{Methodology}

\subsection{Data Source and Description}


The data for this study were collected from a representative crowdsourcing market (CrowdSPRING.com) using a software agent. CrowdSPRING.com is a leading platform for skill-based crowdsourcing activities. Established in 2008, CrowdSPRING.com currently has more than 50,000 crowd seekers and over 190,000 crowd members engaging in various crowdsourcing transactions in four main product categories (Kimbarovsky \& Samson, 2008). The platform has been featured in the New York Times, Forbes and Wall Street Journal for its leading position in the market and the level of enthusiasm it generates among crowdsourcing participants. The final dataset includes 6798 projects successfully completed from 2008 to 2016.

Table 2 displays the operational definitions of the variables of interest in the study. Contest duration is operationalized as length of time in days a project has been listed by a seeker to attract members of the crowd. Contestfitness disconfirmation is the number of bids not accepted for evaluation by the seeker because the bid failed to meet seeker subjective quality threshold. Contest-fitness expectation is operationalized as the number of professionals displayed on the crowdsourcing platform considering or watching a project as they assess their fitness for the contest. Contest performance is the score assigned by the platform operator to a project at the end of the project that depends on the number of participating crowd members and quality of bids submitted.

Control Variables - Project type and project award amount are included as control variables to account for contextual differences among projects. The use of these variables in our models help control for contest specific differences that might affect contest performance. Project types in the study includes web design, mobile design, logo design and product design. The different contests require different strategies, effort and time on the part of the crowd in the construction of bids to be submitted. In addition, these different projects have different rewards. The reward amount (financial award amount) potentially influences expectations of the crowd. Thus, we controlled for the influence of these two factors in the evaluation of our research model. Project type is not included in descriptive statistics in Table 3 or 4 as it is categorical.

Descriptive statistics for data collected (Duan, Gu, \& Whinston, 2008) on the four main quantitative variables and the correlations between the variables are shown in Tables 3 and 4. We applied a log transformation to contest-fitness disconfirmation and contest-fitness expectation due to their skewed and large distribution, updating to variables LnDisconfirmation and LnExpectation. 
Table 2: Variable definitions and measures

\begin{tabular}{|l|l|l|}
\hline Variable & Measurement & Adapted Source \\
\hline $\begin{array}{l}\text { Contest } \\
\text { duration }\end{array}$ & $\begin{array}{l}\text { The length of time in days that it takes a crowd-seeker to find a suitable bid } \\
\text { and close a project contest }\end{array}$ & $\begin{array}{l}\text { Lin \& Huang, } \\
\text { 2010) }\end{array}$ \\
\hline $\begin{array}{l}\text { Contest-fitness } \\
\text { disconfirmation }\end{array}$ & $\begin{array}{l}\text { The number of bids not accepted for consideration in a project contest by } \\
\text { a crowd-seeker }\end{array}$ & $\begin{array}{l}\text { (Anderson } \\
\text { Sullivan, 1993) }\end{array}$ \\
\hline $\begin{array}{l}\text { Contest-fitness } \\
\text { expectation }\end{array}$ & $\begin{array}{l}\text { The number of individuals in the crowd watching a project contest as they } \\
\text { examine their fitness for a crowdsource project contest. }\end{array}$ & Lin \& Huang, (2010) \\
\hline $\begin{array}{l}\text { Contest } \\
\text { performance }\end{array}$ & $\begin{array}{l}\text { The relative score or performance of a project contest to the average } \\
\text { performance of project category as reported by the platform }\end{array}$ & $\begin{array}{l}\text { (Javadi Khasraghi } \\
\text { \& Aghaie, 2014) }\end{array}$ \\
\hline
\end{tabular}

Table 3: Descriptive statistics of variables

\begin{tabular}{|l|c|c|c|c|c|c|}
\hline Variable & $\mathrm{N}$ & Mean & S.D & Min & Median & Max \\
\hline (1) Contest performance & 6798 & 0.96 & 1.97 & -1.5 & 1.11 & 4.38 \\
\hline (2) Contest duration & 6798 & 12.43 & 8.80 & 3 & 11.00 & 58 \\
\hline $\begin{array}{l}\text { (3) Contest-fitness } \\
\text { disconfirmation }\end{array}$ & 6798 & 9.91 & 50.24 & 0.00 & 0.00 & 3153 \\
\hline $\begin{array}{l}\text { (4) Contest-fitness } \\
\text { expectation }\end{array}$ & 6798 & 19.78 & 14.66 & 0.00 & 16.00 & 186 \\
\hline (5) Award & 6798 & 431.52 & 317.44 & 200 & 350 & 3000 \\
\hline
\end{tabular}

Table 4: Correlation table for the variables

\begin{tabular}{|c|c|c|c|c|c|}
\hline Variable & Performance & Duration & Disconfirmation & Expectation & Award \\
\hline $\begin{array}{l}\text { Contest } \\
\text { Performance }\end{array}$ & 1 & & & & \\
\hline Contest Duration & -.016 & 1 & & & \\
\hline $\begin{array}{l}\text { Contest-fitness } \\
\text { Disconfirmation }\end{array}$ & $.071^{* *}$ & $.036^{* *}$ & 1 & & \\
\hline $\begin{array}{l}\text { Contest-fitness } \\
\text { Expectation }\end{array}$ & $.057^{* * *}$ & $.116^{* *}$ & $.268^{* *}$ & 1 & \\
\hline Award & $.049^{* * *}$ & $.044^{* * *}$ & $.144^{* * *}$ & $.528^{* * *}$ & 1 \\
\hline
\end{tabular}

** Correlation is significant at the 0.01 level (2-tailed).

\subsection{Analysis and Results}

To test the hypotheses proposed, data analysis was performed using Preacher and Hayes Process macro in IBM SPSS version 24 software (Hayes, 2012). This method was selected since our model contains several observed exogenous and endogenous variables creating dependencies. The process macro is used for path analysis modeling for observed variables. It uses regression to estimate direct and indirect effects in single/multi-variable model (Hayes, 2013). In addition, a bootstrap procedure with 5,000 re-samples was used to assess the statistical significance of the loadings and of the path coefficients. Preacher and Hayes Process macro is widely used in social, business, and information 
systems research (Hayes \& Scharkow, 2013; Tandoc, Ferrucci, \& Duffy, 2015) for parallel and serial models with two and three way interactions in moderation models for observed data.

Estimation problems such as instability and large variances among coefficient estimates can arise when independent variables are highly correlated (e.g., $80 \%$ or higher) resulting in collinearity among predictor variables (Kennedy, 1998). We determined that the highest correlation between our variables was only 0.528 between award amount and level of expectation among the crowd (as shown in Table 4), which is well below that benchmark. To check the robustness of the results, we conducted a test such as Variance Inflation Factor (VIF) analysis (Kauffman \& Wood, 2006). Our model's variable with the highest VIF was 3.05, which is well below the cutoff of 5 (Hair Jr, Anderson, Tatham, \& William, 1995). Thus, we feel comfortable that our model does not exhibit evidence of multicollinearity.

Table 5 show the results of the path analysis of our model including a list of the estimated coefficients of the path, their significance test based on a two-tailed t-test, and amount of variances explained $\left(\mathrm{R}^{2}\right)$. Approximately 29 percent of the variance in disconfirmation is explained by contest-fitness expectation among the crowd after controlling for award amount and project type. Disconfirmation and expectation explained 15 percent of the variance in contest duration. Contest-fitness expectation, disconfirmation, and contest duration, after controlling for award amount and project type, together explained 13 percent of the variance in contest performance.

Table 5: Analysis results

\begin{tabular}{|l|l|l|l|l|l|l|l|l|l|}
\hline & \multicolumn{3}{|l|}{ Model 1: DV: Disconfirmation } & \multicolumn{3}{l|}{ Model 2: DV: Duration } & \multicolumn{3}{l|}{ Model 3: DV: Performance } \\
\hline Variable & Coef. & t-stat & p-value & Coef. & t-stat & p-value & Coef. & t-stat & p-value \\
\hline Constant & -1.13 & 6.42 & 0.00 & 9.25 & 5.06 & 0.00 & -0.93 & 4.00 & 0.00 \\
\hline LnAward & 0.06 & 1.82 & 0.07 & -0.80 & 2.22 & 0.03 & -0.02 & 0.54 & 0.59 \\
\hline Project_type & 0.25 & 17.01 & 0.00 & -0.62 & 4.05 & 0.00 & -0.62 & 4.05 & 0.00 \\
\hline LnExpectation & 0.37 & 12.31 & 0.00 & 3.21 & 10.34 & 0.00 & 0.13 & 3.44 & 0.00 \\
\hline LnDisconfirmation & & & & 0.38 & 3.00 & 0.00 & 0.16 & 9.17 & 0.00 \\
\hline Duration & & & & & & & -0.004 & 2.26 & 0.02 \\
\hline $\mathrm{R}^{2}$ & 0.29 & & & 0.15 & & & 0.13 & & \\
\hline
\end{tabular}

Table 6: Summary of hypotheses testing

\begin{tabular}{|l|l|l|}
\hline & Hypothesis & Supported \\
\hline H1 & $\begin{array}{l}\text { The level of contest fitness expectation among the crowd in a crowdsourced project } \\
\text { contest is positively associated with the level of contest fitness disconfirmation by } \\
\text { seeker in an intermediary contest-based crowdsourcing market. }\end{array}$ & Supported \\
\hline H2 & $\begin{array}{l}\text { The level of contest fitness disconfirmation in a crowdsourced project contest is } \\
\text { positively associated with contest duration in an intermediary contest-based } \\
\text { crowdsourcing market. }\end{array}$ & Supported \\
\hline
\end{tabular}




\begin{tabular}{|l|l|l|}
\hline H3 & $\begin{array}{l}\text { The level of contest fit disconfirmation in a crowdsourced project contest is positively } \\
\text { associated with contest performance in an intermediary contest-based crowdsourcing } \\
\text { market. }\end{array}$ & Supported \\
\hline H4 & $\begin{array}{l}\text { The level of contest fitness expectation by the crowd in a crowdsourced project contest } \\
\text { is positively associated with the contest duration in an intermediary contest-based } \\
\text { crowdsourcing market. }\end{array}$ & Supported \\
\hline H5 & $\begin{array}{l}\text { The level of contest fitness expectation by the crowd in a crowdsourced project } \\
\text { contest is negatively associated with the contest performance in an intermediary } \\
\text { contest-based crowdsourcing market. }\end{array}$ & $\begin{array}{l}\text { Not } \\
\text { Supported }\end{array}$ \\
\hline H6 & $\begin{array}{l}\text { The contest duration of a crowdsourced project contest is negatively associated with } \\
\text { the project performance in an intermediary contest-based crowdsourcing market. }\end{array}$ & Supported \\
\hline
\end{tabular}

In the first hypotheses, we found support for a significant relationship between level of contest-fitness expectation and contest-fitness disconfirmation ( $\mathrm{H} 1 \beta=0.37, \mathrm{p}<0.01)$. This suggests that as more crowd members are uncertain about their fitness for a contest, the more likely they will craft bids that will not meet the expectations of the crowdseeker. This results in an increased number of disconfirmed bids by the seekers for further evaluation. Hence, hypotheses H1 was supported. Our results show a positive and significant relationship between level of contest fitness disconfirmation and contest duration $(\mathrm{H} 2 \beta=0.38, \mathrm{p}<0.01)$; thus we found support for $\mathrm{H} 2$. This evidence shows that there is a relationship between the decision of a crowd-seeker to close a project ahead of schedule or extend the duration beyond the deadline and the level of bids accepted into the contest. On the other hand, disconfirmation of bids may lead to selective behavior by the crowd which results in crowd member submitting bids only to contests they believe they are likely to win. Such selective behavior by crowd may lead to higher quality bid submission and an overall high performance for contest. Our analysis found support for this relationship in $\mathrm{H} 3$ ( $\mathrm{H} 3 \beta=0.16, \mathrm{p}<0.01$ ). In H4 \& H5, we proposed a relationship between level of contest-fitness expectation by the crowd and two outcome variables-project duration and project performance. The path coefficients for these relationships were positive and significant $(\mathrm{H} 4 \beta=3.21, \mathrm{p}<0.01 ; \mathrm{H} 5 \beta=0.13, \mathrm{p}<0.05)$ suggesting that an increased level of expectations in a contest by the crowd does not only lead to a longer contest length, but a higher performance of the project contest overall. The later result was a surprising result opposite to what was expected. Contrary to what was hypothesized, it is possible that as the crowd watches in anticipation of their fitness during a project contest, they become more selective in which project contest to engage in, although the contest will take a longer time to obtain potential winning bid. The selective nature of crowd members will result in likely submission of quality bids to the contest and subsequent contest score (performance). Finally, this research argued that the duration of a project would influence the performance of project. It is postulated that the longer it takes a seeker to find a suitable bid, the likely the contest performance will be affected. The results indeed indicated that contest duration had a negative effect on contest performance, supporting our last 
hypothesis $(\mathrm{H} 6, \beta=-0.004, \mathrm{p}<0.05)$. This provides evidence that the longer it takes to satisfy seeker needs, the perception of the project performance is negatively affected resulting in a lower score for the project contest.

\section{Discussion}

The ability to attract and maintain a voluntary crowd are critical to the success of any crowdsourcing marketplace (Robert \& Romero, 2017). Successful crowdsourcing contests are key to the sustainability of platforms as well as implementation of crowdsourcing business models in organizations. Considering the bidding process is important because listing and evaluation of submitted bids involves a nontrivial cost to the participants, and these nontrivial costs can affect outcomes and sustainability. We study the determinants of crowdsourcing contest performance that are key to sustainability of the platform as noted in previous research. Two outcomes of crowdsourcing contests that affect sustainability were examined - contest duration and contest performance. Based on ECT we argued that the crowd's expectation about their fitness for a contest and subsequent confirmation or disconfirmation of this expectation are important influencing factors on contest outcomes. Analysis of data from a presentative contest-based crowdsourcing study addressed this important area in crowdsourcing. Specifically, we focused on strategic decision making for platform participants regarding contest-fitness. In particular, crowd seekers need to understand their role in achieving high project contest performance, particularly considering they have the authority to control the dynamics of disconfirmation of crowd bids/expectation.

The empirical results of our analysis support many of the hypotheses in this study. In addition, the results also showed some surprising findings that provide important insights into the crowds' behaviors in auction-like crowdsourcing contests. The confirmation or disconfirmation of the expectations of individuals can affect service performance. Results did show that the number if people evaluating their expectations by observing and analyzing their fitness for contest eventually affects the level of disconfirmation experienced by the crowd seeker in a contest. As the number of people with uncertainties about their fitness increase, the number of submitted bids that may not meet the requirements of the seeker also increase. This results in increased disconfirmation in the crowdsourcing contest.

This study produced interesting unanticipated findings on the direct effect of crowd expectations on contest performance. A surprising relationship was found between contest-fitness expectation and contest performance. We argued that uncertainty about contest fitness among the crowd would lead to poor performance of contest. However, our results show that expectation about contest-fitness leads to better contest performance. The crowd may become 
more selective in the type of project to participate due to fitness uncertainty and will produce a higher quality bid with a higher quality match with their skills set. In essence, following an observation of bid disconfirmation, a crowd member will conduct a cost benefit analysis as their uncertainty is affected by weighing the benefits enumerated by their risk calculation. Because of the non-trivial cost of bid preparation, in light of a bid disconfirmation, crowd members will pay closer attention to the requirements of a project, evaluate the expectation of their fit for the contest more closely, and carefully produce a more suitable bid submission. Additionally, the need to maintain high reputation by the crowd would mean that the crowd would be selective in participating in contest in which they have a high chance of being successful. This would explain the overall enhancement of project and possibly platform performance.

Complementing prior research, we operationalized and used objective measures to verify that expectation confirmation produces desirable outcomes overall (Bhattacherjee \& Premkumar, 2004). Prior literature suggests that tasks that involve a moderate amount of discrepancy or incongruity is beneficial because they stimulate curiosity (Kuo, 2007). Our results indicated that uncertainty by the crowd leads to longer project contest and longer waiting periods for crowd-seekers to receive suitable bids from which to choose the winning bid. However, the long wait is countered by quality of bids following disconfirmation process. Additionally, our results provide insights on the effect of auction (contest) duration which has been has shown to have mixed results (Haruvy \& Leszczyc, 2010). Although a longer duration may lead to the submission of more bids, it will eventually degrade the quality of crowdsourcing contest. One explanation for such an outcome may be due to crowd perceiving the crowd-seeker having unclear project requirements. This finding contributes to auction design parameters/characteristics critical to the sustainability of the auction business model (Mithas \& Jones, 2009), of which intermediary contest-based crowdsourcing business model is based on.

Taken together, the findings of the research as summarized in Table 6 imply that information transparency is important, including publicizing and sanctioning the non-acceptance of bids to be evaluated are important in a contest. Such a move will give the crowd the opportunity to learn from their failed bids. Achieving both learning and performance goals for the crowd results in better outcomes as the natural inclination for all individuals is to lower risk of failure (Kidwell, 2010). This could send signals to the crowd that seekers view their submissions as an investment of effort, create an opportunity for incremental skill development and motivate them to make more strategic decisions. With information transparency for crowd members, crowd seekers can also make better contest fitness decisions 
regarding better bids. With more information available, contest fitness can be improved on all sides and improve contest outcomes, contributing to the sustainability of the crowdsourcing model.

\subsection{Theoretical Implications}

A key difference between our study and prior studies is that we looked at the effects of expectation/confirmation regarding strategic decision making by participants for contest fitness with objective data. We also looked at performance outcomes as noted in prior studies as challenges to sustainability of platforms and organizational implementation. Thus, we contribute to the literature on sustainability. Disconfirmation of expectations has been demonstrated to have a negative effect on participants. However, in a crowdsourcing contest, disconfirmation may have an overall positive effect on the contest outcome. This demonstrates the efficacy of displaying of the number of rejected bids for consideration on project outcome based on the ECT theoretical lens. Thus, we argument in ECT that, post action confirmation influences actor's expectation especially in the context of contest-based crowdsourcing that may lead to submitting quality engagement in activity such as crowding contest. Thus, our results demonstrate the adaptability of ECT literature on virtual communities and traditional group settings to the online crowdsource contest domain.

As crowdsourced contests aim to match demand and supply of labor online, the risk of incurring sunk cost can be reduced, when associated uncertainty is reduced for the crowd. Therefore, platform operators can formulate an optimal strategy that matches seekers' needs and crowds' skills by helping the crowd pre-screen projects they want to observe and eventually participate. Such improved decisions may lead to shorter contest duration and reduce the non-trivial cost that crowd-seeker incur in waiting and evaluating several bids. Such an outcome results in high project performance.

Additionally, since the dynamics of individual unmet expectation is difficult to observe and measure in a competition, we operationalized expectation to be the result of uncertainty in crowds' fitness for a project contest exhibited by the crowd (Lin \& Huang, 2010). We were interested in this proposed dynamic in order to empirically establish the effects of bid disconfirmation on contest-based intermediary crowdsourcing to serve as a basis for understanding contest fitness in order to enhance platform sustainability. Our results present a richer and in depth understanding of expectation disconfirmation especially in the context of online labor market such as intermediary crowdsourcing. This work makes key contributions to expectation confirmation research, a topic that has received 
much attention in IS. In line with research on disconfirmation (Bhattacherjee \& Premkumar, 2004), expectation confirmation produces desirable outcomes in contest-based crowdsourcing overall.

Prior literature suggests that individuals in a transaction/contest are bounded by their resources/capabilities and will make prudent and logical decisions that bring them the most satisfaction (Hastie \& Dawes, 2010). Many crowdseekers use crowdsourcing to generate ideas or obtain quality solutions. The results demonstrate that duration plays an important role in the overall contest performance. The shorter the duration, the higher the contest performance. Shorter duration could enhance performance as intense bidding among the crowd result in higher quality bid submissions in the contest.

\subsection{Practical Implications}

Managing expectations for strategic decision making is an important consideration to ensure successfully operated crowdsourcing platforms. Prior IS research has noted the importance of managers setting achievable, realistic expectations (Venkatesh \& Goyal, 2010), and the results of the study also provide a set of practical insights along these lines for intermediary crowdsourcing platforms. First, the objective of the operator of a crowdsourcing contest is to ensure project success. Since the crowd easily sees the number of rejected bids for consideration, an operator can consider system enhancement for more context regarding rejected bids, or project requirements. Secondly, our results delineate a pathway to improve the score of a project. Since contest-fitness expectation has been found to affect project score, managers of contest-based crowdsourcing may want to encourage the crowd to participate in a project even when they believe they do not possess the requisite skills but ensure that the bid is well researched and executed. This could improve the crowdsource skills set and quality and ultimately reduce the duration of project and improve its performance.

\section{Conclusion}

Online global labor markets such as contest-based intermediary crowdsourcing markets serve as intermediaries that help companies to find service providers (e.g., web developers and graphical designers). As an emerging business model, it has attracted the interest of industry and researchers (Leimeister et al., 2009). Our use of observed data from one contest-based crowdsourcing may limit the generalizability of the results despite providing a baseline for further inquiry. Other factors such as crowd member cognitive capital prior to joining the platform may affect their nonparticipation or the timing of a project launch may affect its duration or performance. 
Despite the preceding the limitations, we respond to the call by Chiu, Liang, \& Turban (2014) to examine crowdsourcing success challenges related to project and crowd fitness by examining the effect of contest fitness antecedents on performance. By exploring a representative intermediary crowdsourcing market, we help advance the use of open contests to complement internal workforce by developing a framework that explores strategic decision making of participants that the market operator must take into consideration when designing appropriate labor markets to facilitate online contests as a more streamlined and effective innovative enhancement to organizations.

\section{References}

Anderson, E. W., \& Sullivan, M. W. (1993). The Antecedents and Consequences of Customer Satisfaction for Firms. Marketing Science, 12(2), 125-143.

Bayus, B. L. (2013). Crowdsourcing New Product Ideas over Time: An Analysis of the Dell IdeaStorm Community. Management Science, 59(1), 226-244.

Bhattacherjee, A. (2001). Understanding Information Systems Continuance: An Expectation-Confirmation Model. MIS Quarterly, 25(3), 351.

Bhattacherjee, A., \& Premkumar, G. (2004). Understanding Changes in Belief and Attitude Toward Information Technology Usage: A Theoretical Model and Longitudinal Test. MIS Quarterly, 28(2), 229-254.

Bolton, G., Loebbecke, C., \& Ockenfels, A. (2008). Does competition promote trust and trustworthiness in online trading? An experimental study. Journal of Management Information Systems, 25(2), 145-170.

Boudreau, K. J., Lacetera, N., \& Lakhani, K. R. (2011). Incentives and Problem Uncertainty in Innovation Contests: An Empirical Analysis. Management Science, 57(5), 843-863.

Brown, S. A., Venkatesh, V., \& Goyal, S. (2012). Expectation Confirmation in Technology Use. Information Systems Research, 23(2), 474-487.

Bullinger, A. C., Neyer, A.-K., Rass, M., \& Moeslein, K. M. (2010). Community-Based Innovation Contests: Where Competition Meets Cooperation: Community-Based InnovationContests. Creativity and Innovation Management, 19(3), 290-303.

Chanal, V., \& Caron-Fasan, M.-L. (2010). The difficulties involved in developing business models open to innovation communities: the case of a crowdsourcing platform. M@n@gement, 13(4), 318-340.

Chawla, S., Hartline, J. D., \& Sivan, B. (2015). Optimal crowdsourcing contests. Games and Economic Behavior. $13,80-96$

Cheung, C. M. K., \& Lee, M. K. O. (2009). Understanding the Sustainability of a Virtual Community: Model Development and Empirical Test. Journal of Information Science, 35(3), 279-298.

Chiu, C.-M., Liang, T.-P., \& Turban, E. (2014). What can crowdsourcing do for decision support? Decision Support Systems, 65, 40-49.

Djelassi, S., \& Decoopman, I. (2013). Customers' participation in product development through crowdsourcing: Issues and implications. Industrial Marketing Management, 42(5), 683-692.

Duan, W., Gu, B., \& Whinston, A. B. (2008). Do online reviews matter? - An empirical investigation of panel data. Decision Support Systems, 45(4), 1007-1016.

Geiger, D., \& Schader, M. (2014). Personalized task recommendation in crowdsourcing information systems Current state of the art. Decision Support Systems, 65, 3-16.

Giles, M. (2018, August 23). Crowdsourcing the hunt for software bugs is a booming business-and a risky one. MIT Technology Review. Retrieved from https://www.technologyreview.com/s/611892/crowdsourcing-thehunt-for-software-bugs-is-a-booming-businessand-a-risky-one/

Gräuler, M., Freundlieb, M., Ortwerth, K., \& Teuteberg, F. (2013). Understanding the Beliefs, Actions and Outcomes of Sustainability Reporting: An Experimental Approach. Information Systems Frontiers, 15(5), 779-797.

Hair Jr, J. F., Anderson, R. E., Tatham, R. L., \& William, C. (1995). Multivariate data analysis with readings. New Jersey: Prentice Hall.

Haruvy, E., \& Leszczyc, P. T. L. P. (2010). The Impact of Online Auction Duration. Decision Analysis, 7(1), 99106. 
Hastie, R., \& Dawes, R. M. (2010). Rational choice in an uncertain world: The psychology of judgment and decision-making. Sage.

Hayes, A. F. (2012). My macros and code for SPSS and SAS. Retrieved from URL: http://afhayes. com/spss-sasandmplus-macros-and-code. html

Hayes, A. F. (2013). Introduction to mediation, moderation, and conditional process analysis. New York: Guilford Press.

Hayes, A. F., \& Scharkow, M. (2013). The relative trustworthiness of inferential tests of the indirect effect in statistical mediation analysis: Does method really matter?. Psychological Science, 24(10), 1918-1927.

Javadi Khasraghi, H., \& Aghaie, A. (2014). Crowdsourcing contests: understanding the effect of competitors' participation history on their performance. Behaviour \& Information Technology, 33(12), 1383-1395.

Kajino, H., Arai, H., \& Kashima, H. (2014). Preserving worker privacy in crowdsourcing. Data Mining and Knowledge Discovery, 28(5-6), 1314-1335.

Kauffman, R. J., \& Wood, C. A. (2006). Doing their bidding: An empirical examination of factors that affect a buyer's utility in Internet auctions. Information Technology and Management, 7(3), 171-190.

Kennedy, P. (1998). A guide to econometrics (4th ed). Cambridge, Mass: MIT Press.

Kidwell, R. E. (2010). Loafing in the 21st century: Enhanced opportunities — and remedies — for withholding job effort in the new workplace. Business Horizons, 53(6), 543-552.

Kim, D. J., Ferrin, D. L., \& Rao, H. R. (2008). A trust-based consumer decision-making model in electronic commerce: The role of trust, perceived risk, and their antecedents. Decision Support Systems, 44(2), 544564.

Kimbarovsky, R., \& Samson, M. (2008). crowdSPRING, LLC. Retrieved from www.crowdspring.com

Klein, S., \& Teubner, R. A. (2000). Web-based procurement new roles for intermediaries. Information Systems Frontiers, 2(1), 19-30.

Kuo, M.-J. (2007). How does an online game based learning environment promote students' intrinsic motivation for learning natural science and how does it affect their learning outcomes? Digital Game and Intelligent Toy Enhanced Learning, 2007. DIGI ${ }^{T E L}$ '07. The First IEEE International Workshop On, 135-142.

Lankton, N. K., McKnight, D. H., Wright, R. T., \& Thatcher, J. B. (2016). Research Note-Using Expectation Disconfirmation Theory and Polynomial Modeling to Understand Trust in Technology. Information Systems Research, 27(1), 197-213.

Leimeister, J. M., Huber, M., Bretschneider, U., \& Krcmar, H. (2009). Leveraging crowdsourcing: activationsupporting components for IT-based ideas competition. Journal of Management Information Systems, 26(1), 197-224.

Lin, T.-C., \& Huang, C.-C. (2010). Withholding effort in knowledge contribution: The role of social exchange and social cognitive on project teams. Information \& Management, 47(3), 188-196.

Liu, T. X., Yang, J., Adamic, L. A., \& Chen, Y. (2014). Crowdsourcing with all-pay auctions: a field experiment on taskcn. Management Science, 60(8), 2020-2037.

McKinney, V., Yoon, K., \& Zahedi, F. "Mariam.” (2002). The Measurement of Web-Customer Satisfaction: An Expectation and Disconfirmation Approach. Information Systems Research, 13(3), 296-315.

Mithas, S., \& Jones, J. L. (2009). Do Auction Parameters Affect Buyer Surplus in E-Auctions for Procurement? Production and Operations Management, 16(4), 455-470.

Oliver, R. L. (1977). Effect of Expectation and Disconfirmation on Postexposure Product Evaluations: An Alternative Interpretation. Journal of Applied Psychology, 62(4), 480-486.

Oliver, R. L. (1980). A Cognitive Model of the Antecedents and Consequences of Satisfaction Decisions. Journal of Marketing Research, 17(4), 460-469.

Pe-Than, E. P. P., Goh, D. H.-L., \& Lee, C. S. (2017). Does it matter how you play? The effects of collaboration and competition among players of human computation games. Journal of the Association for Information Science and Technology, 68(8), 1823-1835.

Robert, L. P., \& Romero, D. M. (2017). The influence of diversity and experience on the effects of crowd size. Journal of the Association for Information Science and Technology, 68(2), 321-332.

Satzger, B., Psaier, H., Schall, D., \& Dustdar, S. (2013). Auction-based crowdsourcing supporting skill management. Information Systems, 38(4), 547-560.

Schenk, E., \& Claude, G. (2011). Towards a characterization of crowdsourcing practices. Journal of Innovation Economics \& Management, 1, 93-107.

Schonfeld, E. (2008, May 12). When Crowdsourcing Fails: Cambrian House Headed to the Deadpool. CrunchBase. Retrieved from https://techcrunch.com/2008/05/12/when-crowdsourcing-fails-cambrian-house-headed-tothe-deadpool/ 
Simon, H. A. (1978). Rationality as process and as product of thought. The American Economic Review, 1-16.

Tandoc, E. C., Ferrucci, P., \& Duffy, M. (2015). Facebook use, envy, and depression among college students: Is facebooking depressing? Computers in Human Behavior, 43, 139-146.

Taylor, P. (2017, March). Crowdsourcing Service Providers. Retrieved from http://clients1.ibisworld.com/reports/us/industry/ataglance. aspx?entid=5672

Venkatesh, \& Goyal. (2010). Expectation Disconfirmation and Technology Adoption: Polynomial Modeling and Response Surface Analysis. MIS Quarterly, 34(2), 281.

Venkatesh, V., Thong, J. Y. L., Chan, F. K. Y., Hu, P. J.-H., \& Brown, S. A. (2011). Extending the Two-Stage Information Systems Continuance Model: Incorporating UTAUT Predictors and the Role of Context: Context, Expectations and IS Continuance. Information Systems Journal, 21(6), 527-555.

Xiao, L. (2014). Effects of rationale awareness in online ideation crowdsourcing tasks: Journal of the American Society for Information Science and Technology. Journal of the Association for Information Science and Technology, 65(8), 1707-1720.

Yu, J., Zo, H., Kee Choi, M., \& P. Ciganek, A. (2013). User acceptance of location-based social networking services: An extended perspective of perceived value. Online Information Review, 37(5), 711-730.

Zheng, H. (2014). Antecedents Of Solution Quality In Crowdsourcing: The Sponsor's Perspective. Journal of Electronic Commerce Research, 15(3), 14.

Zheng, H., Li, D., \& Hou, W. (2011). Task Design, Motivation, and Participation in Crowdsourcing Contests. International Journal of Electronic Commerce, 15(4), 57-88. 